\title{
Errata
}

\section{A set of polarized parton distributions}

\author{
P.M. Nadolsky
}

Institute for High Energy Physics, 142284 Protvino, Moscow Region, Russia

Z. Phys. C63 (1994) 601-609

The inverse values of the ratio $F_{2}^{p}\left(x, Q^{2}\right) / F_{2}^{n}\left(x, Q^{2}\right)$ were given instead of the correct ones. The ratio $F_{2}^{p}\left(x, Q^{2}\right) /$ $F_{2}^{n}\left(x, Q^{2}\right)$ should be substituted by $F_{2}^{n}\left(x, Q^{2}\right) / F_{2}^{p}\left(x, Q^{2}\right)$ everywhere where its numerical value is quoted (p. 603, column 2 , lines 19 and $34 ;$ p. 607, column 2 , line 2 from below).

\section{Determination of the strange quark content of the nucleon from a next-to-leading-order QCD analysis of neutrino charm production}

\author{
A.O. Bazarko et al., CCFR Collaboration
}

Columbia University, New York, NY 10027, USA

Z. Phys. C65 (1995) 189-198

A citation was omitted from the fifth paragraph in the left column on page 192. The paragraph should have concluded with a reference to V. Barone, M. Genovese, N. Nikolaev, E. Predazzi, and B. Zakharov, Phys. Lett. B 328 (1994) 143.

Zeitschrift für Physik C - Particles and Fields is delivered to some institutions in the former Soviet Union through a program initiated and administered by the European Physical Society and supported by the publisher. This program is funded by INTAS, the international association for the promotion of cooperation with scientists from the independent States of the former Soviet Union. Members of INTAS are the European Union, Austria, Belgium, Denmark, Finland, France, Germany, Greece, Ireland, Italy, Luxembourg, The Netherlands, Portugal, Spain, United Kingdom and Switzerland. (INTAS, rue du Luxembourg 14A, 1040 Bruxelles, Belgique). 